\title{
Ethanol Production from Gmelina arborea Wood Wastes by Saccharomyces cerevisiae using Submerged Fermentation
}

\author{
Adedayo, M. R. ${ }^{1 *}$ Ajiboye, A. E. ${ }^{1}$ and Yahaya, O. A. ${ }^{1}$ \\ ${ }^{1}$ Kwara State University, Department of Biosciences and Biotechnology, Microbiology Unit, PMB 1530, \\ Malete, Nigeria +2348133325627 . \\ ${ }^{1}$ Kwara State University, Department of Biosciences and Biotechnology, Microbiology Unit, PMB 1530, \\ Malete, Nigeria +2348061102397 \\ ${ }^{1}$ Kwara State University, Department of Biosciences and Biotechnology, Microbiology Unit, PMB 1530, \\ Malete, Nigeria
}

\begin{abstract}
Lignocellulose wastes are the most abundant residues on the surface of the earth. This project studies the possibility of ethanol production from a forestry waste. Wood wastes from Gmelina arborea were treated with dillute sulfuric acid to break down the lignin component. Fermentation for ethanol production was done using baker's yeast (Saccharomyces cerevisiae ATCC 204508/S288c) for 120 hours using submerged fermentation, and the $\mathrm{pH}$, reducing sugar, specific gravity and lignin content were determined using standard techniques. Ethanol concentration and yield were measured via vinometer and ethanol standard curve techniques. From the results, the highest pH was obtained at $\mathbf{7 2}$ hours of the fermentation period. The reducing sugar content and specific gravity decreased over the fermentation time. The acid-pretreated wood wastes gave a maximum ethanol concentration of $3.84 \%$ and a yield of $7.60 \mathrm{ml} / \mathrm{g}$ as measured from the vinometer and ethanol standard curve methods at 72 and 96 hours of fermentation, respectively. About $13.6 \% \mathrm{v} / \mathrm{v}$ of ethanol was recovered from the distillation process employed to separate the components of the product generated after fermentation. The observations in this research reveal the possibility of producing ethanol from $G$. arborea wood wastes and under optimized culture conditions. This could serve as an alternate means of biofuel generation and hence value addition to the wastes.
\end{abstract}

Keywords: Gmelina arborea, Saccharomyces cerevisiae, Ethanol, Submerged fermentation *Corresponding author: *Majekodunmi Racheal Adedayo; majekodunmi.adedayo@kwasu.edu.ng

\section{Introduction}

Bioethanol production has been the interest of modern-day scientists who are constantly searching for alternative, ecofriendly and renewable sources of energy (Saini et al., 2015; Priyanka et al., 2019; Kumar et al., 2020). There is a recent global drift to the search for alternate sources of fuel for energy-based industries. However, corn, the main substrate exploited for producing bioethanol in the industries, is a starch-based food for man and livestock. A major problem with today's conventional (grainbased) biofuels production is that they result in competition for grain with food purposes, potentially hiking up the price of grain-foods (Scully and Orlygsson, 2014). Also, environmental issues in corn production revolve around erosion, pesticide and chemical fertilizer use (Priyanka et al., 2019). The major problem of fossil fuels as energy sources is environmental pollution as it leads to increase in greenhouse gas (GHG) emissions and ultimate loss of the ozone layer through emission of potentially hazardous radiations (Priyanka et al., 2019). Non- crop cellulosic materials give a promising alternative source for bioethanol. Producing ethanol from cellulosic 
wastes as raw materials is profitable due to its abundance, less expensive and diverse nature as against corn. It also decreases greenhouse gas effects as well as solving the problem of environmental pollution and waste management (Sainz, 2011; Priyanka et al., 2019; Kumar et al., 2020).

Fermentation breaks down sugar to release energy (Tortora et al., 2010). Fermentation for ethanol production is the conversion of glucose directly to ethanol and carbon dioxide. Solid state fermentation (SSF) involves growing microorganisms directly on substrates with low quantities of water (Cavalieri et al., 2003). It is widely accepted and used in many industries for several processes (Durand, 2003). On the other hand, Submerged fermentation is the immersion of microorganisms in liquid medium for the manufacture of a desired product (Fang and Zhong, 2002; Tortora et al., 2010). In submerged fermentation, bioactive substances are secreted directly into the fermentation broth, uniformity in fermentation parameters is also enhanced (Subramaniyam and Vimala, 2012).

Ethanol is a colourless and almost odourless water- soluble liquid. It is highly flammable and very volatile; hence it evaporates easily when left open. Generally, it has the formula $\mathrm{C}_{2} \mathrm{H}_{6} \mathrm{OH}$ (Becker, 2013). Making ethanol from agro-wastes and other cellulosic materials have several undisputable benefits over the conventional method of using corn (Yanowitz and Mc Cormick, 2009). Ethanol is used as an antiseptic, solvent, fuel, and due to its low freezing point, the active fluid in many alcohol thermometers (Becker, 2013)

There are several microorganisms with the ability of producing ethanol (Lin and Tanaka, 2006). Sacharomyces sp, Zymomonas mobilis (Orji et al., 2016) and Escherichia coli are among the notable ones. Saccharomyces cerevisiae and Zymomonas mobilis are yeasts, with a known capacity of breaking down sugar to produce ethanol. The organisms have high affinity and tolerance for alcohol. Saccharomyces cerevisiae is a unicellular yeast, able to perform both aerobic and anaerobic respiration, hence it stands out for ethanol production (Yanase et al., 2005).

Lignocellulosic biomass and starch materials have been used for bioethanol production (Priyanka et al., 2019). Gmelina arborea is a woody tree, found in many parts of the world and it grows all-round the year with special ability to survive drought (Conn and Barry, 2001; Gangadharan, 2012). In Nigeria, the yield of $252 \mathrm{~m}^{3} / \mathrm{ha}$ in favourable soil condition has been documented (Adegbehin et al., 1988); the yield could also be as high as 304 $\mathrm{m}^{3} / \mathrm{ha}$ (Adam and Krampah, 2005). The waste generated was estimated to be about $35 \%$ (Larinde and Aiyeloja, 2014).

Wastes from this wood is enormously generated yearly, most often burnt in the open air, causing environmental pollution and increase in cost of waste treatment. Using this waste as a source of fermentable sugar for bioethanol production will remedy the menace. The aim of this research therefore is to investigate the potential use of lignocellulosic material (wood waste from Gmelina arborea) in the fermentation process for the production of ethanol.

\section{Materials and Methods}

\section{Sample Collection/Authentication of wood discards}

Wood wastes (saw dust) from Gmelina arborea was collected from a saw mill at Ilorin, Kwara State. The leaf and bark of the Gmelina arborea were identified and authenticated at the Herbarium of the Department of Plant Biology, University of Ilorin, where the voucher numbers UILH/001/985 and UILH/021/357 respectively were signed to them for reference purpose.

\section{Pretreatment}

In this phase, the size of the wood discard was reduced by sieving with a sieve of $0.5 \mathrm{~mm}$ pore diameter to give a uniform size.

\section{Acid Hydrolysis}

The pretreated wood discard was degraded using both dilute and concentrated sulfuric acids. Ten grams of the wood discard was introduced into the dilute sulfuric acid $(1.5 \%)$ which was obtained by mixing $\quad 98.5 \mathrm{ml}$ of water with $1.5 \mathrm{ml}$ of concentrated sulfuric acid. The solution was heated to $160^{\circ} \mathrm{C}$ for 30 minutes. In this process, the hemicellulose was hydrolyzed into sugar monomers and was recovered in the liquid fraction by passing it through No 1 Whatman filter paper. After filtration, the residual solids which contain cellulose and lignin were 
introduced into a relatively lower concentration of sulfuric acid $(0.4 \%)$ which was obtained by mixing $\quad 99.6 \mathrm{ml}$ of water in $0.4 \mathrm{ml}$ of concentrated sulfuric acid. The solution was further subjected to hydrolysis at a high temperature of $213{ }^{\circ} \mathrm{C}$ in an oven for 6 hours. The product was filtered using the same procedure as described above to separate the filtrate from the residue. Sugar monomers (sugar hydrolysate) obtained during the course of the hydrolysis were subjected to microbial fermentation (Chen et al., 2007).

\section{Determination of lignin content}

The solid material remaining after hydrolysis was considered as lignin. This was filtered and washed severally with distilled water. It was dried at $105^{\circ} \mathrm{C}$ until constant weight was obtained. The lignin content (\%) standard curve method and the vinometer was expressed by using the following equation method which were described below. To assay (Talebnia et al., 2010).

$$
=\frac{\begin{array}{c}
\text { Lignin content }(\%) \\
\text { weight of residue }(\mathrm{g})
\end{array}}{\text { weight of sample }(\mathrm{g})} \times 100 \%
$$

\section{Fermentation}

\section{Inoculum (yeast) development}

Dry baker's yeast (Saccharomyces cerevisiae ATCC 204508/S288c) was obtained from Dangote flour mill PLC, Ilorin, Kwara State, Nigeria. Ten grams of yeast peptone dextrose agar was prepared and sterilized in an autoclave at $121^{\circ} \mathrm{C}$ for 15 minutes. Two grams of the dry yeast was grown on the agar plate at $30^{\circ} \mathrm{C}$ for 48 hours to activate the yeast. A loop ful of the yeast colony was transferred from the agar plate into $100 \mathrm{ml}$ of $5 \%$ yeast peptone dextrose broth (which was obtained by dissolving 5 grams of the broth in $100 \mathrm{ml}$ of solution using distilled water) and incubated at $28 \pm 2{ }^{\circ} \mathrm{C}$ on a shaker (Stuart Orbital Shaker SSL1) at $130 \mathrm{rpm}$ for 48 hours. Precisely $7 \mathrm{ml}$ of the broth was centrifuged at 4,500 rpm for 5 minutes. The supernatant was decanted and the pellet was resuspended in $10 \mathrm{ml}$ of sterile distilled water twice and centrifuged. The pellet was resuspended in $1 \% 50 \mathrm{ml}$ citrate buffer and was used as inoculum (Suh et al., 2007).

\section{Ethanol fermentation process}

Two milliliters of the yeast suspension in the citrate buffer was added to $50 \mathrm{ml}$ of the sterile sugar monomers obtained after hydrolysis, contained in a conical flask and clogged with cotton wool. It was aerated by placing it on an orbital shaker at $250 \mathrm{rpm}$ for 120 hours. Fermentation was carried out for a period of 120 hours at $28 \pm 2{ }^{\circ} \mathrm{C}$. After every 24 hours, the samples were aseptically withdrawn from the fermentation medium, centrifuged at 4,500 rpm for 6 minutes. $\mathrm{pH}$, reducing sugar content, specific gravity and ethanol yield were determined using the filtrate obtained with the aid of a vinometer and ethanol standard curve assay method (Abouzeid and Reddy, 2006).

\section{Assay for Ethanol yield and concentration}

This was carried out using the ethanol for ethanol yield, $5 \mathrm{ml}$ of the fermented liquid was centrifuged at 4,500 rpm for 6 minutes. Two $\mathrm{ml}$ of ethanol assay reagent (Pottasium dichromate reagent) was added to each of 3 cuvettes. Ten $\mu$ l of distilled water was added to the first cuvette to make up the blank and $10 \mu \mathrm{l}$ of Ethanol standard $(0.8 \% \mathrm{v} / \mathrm{v})$ was added to the second cuvette to make up the standard. Ten $\mu \mathrm{l}$ of the supernatant solution was added to the third cuvette. These cuvettes were incubated at room temperature for 10 minutes. The absorbance of each cuvette was read at $340 \mathrm{~nm}$, using the blank to zero the spectrophotometer (Spectrophometer LI-722). Ethanol concentration of the solution was calculated using the formula below and read from the standard curve (Williams and Reese, 2005).

0.8

$$
\text { Ethanol }(\mathrm{ml} / \mathrm{g})=\frac{\text { Absorbance }(\text { sample })}{\text { Absorbance }(\text { standard })} \mathrm{X}
$$

\section{Ethanol assay using Vinometer}

The centrifuged fermented liquor was poured into the funnel at the top of the vinometer (Vinometer FIW $130-25 \%$ ) until it was approximately half- full. The vinometer was held up with the funnel until 6 drops of the sample fell from the tip. Immediately after the drops came out, the tester was inverted by pouring the remaining liquid out of the funnel and it was continued to be held upside down. The liquid contained in the vinometer tube descended slowly and later stopped. The percentage concentration of ethanol on the scale was read and recorded (Abouzeid and Reddy, 2006). 
maintained at $78.4{ }^{\circ} \mathrm{C}$ a temperature at which the ethanol vapourized in a distilling flask. The

The $\mathrm{pH}$ of each sample during the 120 vapour which is mostly ethanol was trapped in hours of fermentation was determined every 24 hours the condenser which was connected to the using a pH meter ( $\mathrm{pH}$ metre model: OHAUZ STARTAR fractionating column of the distilling flask. The 2000). Five ml of each solution was pipetted into a 200 vapour was later condensed back to ethanol and $\mathrm{ml}$ conical flask and the electrode was dipped into it. was received in a round-bottom flask. Thus, $\mathrm{pH}$ of the samples was read and recorded (Abouzeid ethanol produced was recovered after and Reddy, 2006).

fermentation of the sample.

Determination of reducing sugar content (brix level) and specific gravity

This was done using the refractometer hemicellulose) content of the sample was found method. The front end of the refractometer to be $23.7 \%$ as presented in Table 1.The (Refractometer RF 110) was aimed in the direction of results obtained from the measurement of a bright light, and the adjusting ring of the diopter was ethanol yield using ethanol standard curve as adjusted until the reticle can be seen clearly. The shown in Table 2. There was an increase in refractometer was calibrated by opening the cover ethanol yield from 24 hours to 96 hours plate and two drops of distilled water was placed on fermentation period with a maximum ethanol the prism using a dropping pipette. The cover plate was yield of $7.60 \mathrm{ml} / \mathrm{g}$ recorded at 96 hours closed, pressed lightly, rotated and the calibration fermentation period. This was followed by a screw was adjusted to make the light/blue boundary drop in ethanol yield after 120 hours of (made up of the brix level and specific gravity scale) fermentation. Readings on the vinometer with the null line. The cover plate was opened and the recorded ethanol yield of the sample quantity in surface of the prism was cleaned with a piece of cotton percentage (\%). Percentage yield increased wool. Two drops of the sample to be measured was until the peak was reached at 72 hours dropped on the prism, the cover plate was covered, fermentation period and then it declined pressed lightly and the corresponding scale of the (Table 3 ). The $\mathrm{pH}$ was fluctuating during light/blue boundary was read and recorded (Abouzeid fermentation (Table 4). The results presented and Reddy, 2006).

\section{Recovering ethanol through distillation}

The ethanol produced was separated from the water using fractional distillation. Since the boiling point of ethanol is $78.4 \mathrm{OC}$ while that of water is $100{ }^{\circ} \mathrm{C}$, the mixture was in Tables 5 and 6 showed that the reducing sugar content and specific gravity of the sample decreased generally throughout the fermentation period, with the least records observed at 120 hours of fermentation. The recovered ethanol after distillation was $13.8 \%$ $\mathrm{v} / \mathrm{v}$ of the sample fermented.

Table 1: Residual content of the sample

\begin{tabular}{|ccc|}
\hline Weight of sample $(\mathrm{g})$ & Weight of residue $(\mathrm{g})$ & Percentage content (\%) \\
\hline 10 & 2.37 & 23.7 \\
\hline
\end{tabular}

Table 2: Ethanol Yield (Measured from Standard Curve and Vinometer)

\begin{tabular}{|l|l|l|}
\hline $\begin{array}{l}\text { Duration of } \\
\text { fermentation (Hours) }\end{array}$ & $\begin{array}{l}\text { Ethanol yield }(\mathrm{ml} / \mathrm{g}) \\
\text { (Standard curve) }\end{array}$ & \\
\hline 24 & $4.30 \pm 0.60^{\mathrm{a}}$ & $1.98 \pm 0.22^{\mathrm{b}}$ \\
\hline 48 & $5.07 \pm 0.89^{\mathrm{a}}$ & $2.77 \pm 0.39^{\mathrm{b}}$ \\
\hline 72 & $6.73 \pm 0.43^{\mathrm{a}}$ & $3.84 \pm 0.39^{\mathrm{b}}$ \\
\hline
\end{tabular}




\begin{tabular}{|l|l|l|}
\hline 96 & $7.60 \pm 0.90^{\mathrm{a}}$ & $3.58 \pm 0.32^{\mathrm{b}}$ \\
\hline 120 & $6.62 \pm 0.39^{\mathrm{a}}$ & $3.13 \pm 0.44^{\mathrm{b}}$ \\
\hline
\end{tabular}

Data are means of two replicates \pm standard error of mean (SEM). Data within the same row carrying different superscript are significantly different at $\mathrm{P}<5$

Table 3: $\mathrm{pH}$ of sample during fermentation

\begin{tabular}{|cc|}
\hline $\begin{array}{c}\text { Duration of fermentation } \\
\text { (hrs) }\end{array}$ & $\mathrm{pH}$ \\
\hline 24 & $4.57 \pm 0.31$ \\
48 & $4.31 \pm 0.33$ \\
72 & $4.95 \pm 0.80$ \\
96 & $4.27 \pm 0.14$ \\
120 & $4.49 \pm 0.29$ \\
\hline
\end{tabular}

Data are means of two replicates \pm standard error of mean (SEM)

Table 4: Reducing sugar content of sample during fermentation

\begin{tabular}{|cc|}
\hline Duration of fermentation & Reducing sugar content (brix level) \\
(hrs) & $(\%)$ \\
\hline 24 & $4.05 \pm 0.45$ \\
48 & $3.56 \pm 0.13$ \\
72 & $3.12 \pm 0.27$ \\
96 & $2.77 \pm 0.43$ \\
120 & $2.43 \pm 0.51$ \\
\end{tabular}

Data are means of two replicates \pm standard error of mean (SEM)

Table 5: Specific gravity of sample during fermentation 


\begin{tabular}{|ll|}
\hline 24 & $1.31 \pm 0.01$ \\
48 & $1.07 \pm 0.07$ \\
72 & $1.00 \pm 0.00$ \\
96 & $1.00 \pm 0.00$ \\
120 & $0.92 \pm 0.06$ \\
& \\
\hline
\end{tabular}

Data are means of two replicates \pm standard error of mean (SEM)

\section{Discussion}

The purpose of pretreatment on the sample was to convert the polysaccharides (Cellulose and Hemicellulose) in the wood discard into fermentable sugar monomers for effective conversion to alcohol by the inoculated yeast. The acid pretreatment enhances the quantity of the monomers released during hydrolysis of the polysaccharide. The application of acid (sulfuric acid) for the pretreatment breaks the complex bond in the lignocellulosic material and enhances more access of the fermenting yeast to the sugar monomers as reported by earlier authors (Rodrigues et al., 1998). This observation correlates with the report of Rodrigues et al. (1998) where a total of 40 wood samples were utilized. The residual content is the unhydrolyzed cellulose, hemicellulose and lignin.

The sugar monomers were utilized to produce ethanol by the yeast as recorded in Table 2 . Generally, there was an increasing trend in ethanol yield, a peak was attained, followed by decrease in ethanol yield. This was contrary to the report of Michelle (2011) where ethanol yield from corn stover increased throughout the period of fermentation. The reasons for the differences in yield may be attributed to the fermentation conditions as well as the method employed to assay for ethanol. The reason for the decrease in yield could be attributed to the growth phases of the fermenting yeast. The organism was at its late phase of exponential growth and progressing to the stationary phase. At this moment most of the sugar monomers have been converted into alcohol, hence, there is limited reducing sugar present in the sample coupled with accumulation of metabolic waste and increase in alcohol concentration. During this period, the activity of the yeast and fermentation have reduced drastically. Low substrate concentration can lead to energy deprivation and reduction in metabolic activities by the starving yeasts. Hence the rate at which fermentation occurs is reduced. This observation agrees with the finding of Martin et al. (2002). From the results of ethanol yield obtained from both assay methods, the standard curve method produced a higher percentage yield of ethanol when compared to the vinometer. Therefore, of the two assay methods, the ethanol standard curve method could be considered to be more sensitive .

The $\mathrm{pH}$ of the sample fluctuates during the 120 hours fermentation period. The acidic $\mathrm{pH}$ recorded during fermentation, however, enhances ethanol production and it also serves as a deterrent to bacterial contaminants (Palmqvist, 2000). The $\mathrm{pH}$ of the reaction fluctuates as ethanol and other products are released into the solution.

The results in Tables 4 and 5 show the change pattern of reducing sugars and specific gravity during the fermentation period, respectively. The reducing sugars were the direct substrates converted into alcohol by the yeast, the concentration of which determines the rate and the quantity of the alcohol produced. The reducing sugars in the fermentation medium were observed to decrease with progressive increase in fermentation period. This is so because the yeast depends on the sugars for its energy and subsequently to produce ethanol. As incubation period increases, cell activity increases and the reduction in reducing sugar levels also increases rapidly and more alcohol is produced. The depletion in the reducing sugar content and specific gravity followed the same pattern. The 
fermentation of the total soluble solid into ethanol was responsible for the decrease in specific gravity. This observation agrees with the findings of Okeke and Obi (1994) in which sugar level and specific gravity of agro-waste decreased, respectively, throughout the fermentation periods.

Most often, the quantity of ethanol yield depends on the substrate, pretreatment method, fermenting organism and the fermentation parameters. In this research only $13.6 \% \mathrm{v} / \mathrm{v}$ of the sample fermented was recovered in the form of ethanol. This report however does not agree with an earlier record on ethanol yield (Akpan et al., 2005). Differences in the substrates used and laboratory conditions could account for the variation in the amount of ethanol generated.

The experimental data observed suggested that wood discard from Gmelina arborea could be a potential substrate for ethanol production under optimized fermentation conditions.

\section{Conclusion}

The experimental results obtained in this work showed that wood discard from Gmelina arborea could be a viable substrate to produce ethanol given that hydrolysis and fermentation processes are optimized. It could therefore be recommended that fermenting organism and culture conditions be optimised for maximum ethanol yield using the wood discard.

\section{References}

Abouzeid, M.M. and Reddy, A. (2006). Direct fermentation of potato starch to ethanol by cocultures of Aspergillus niger and Saccharomyces cerevisiae. J. of App. and Envt. Micro., 52 (3): 1055-1059.

Adam, K.A. and Krampah, E., (2005). Gmelina arborea Roxb. ex Sm. In: Louppe, D., OtengAmoako, A.A. and Brink, M. (Editors). PROTA (Plant Resources of Tropical Africa / Ressources végétales de l'Afrique tropicale), Wageningen, Netherlands. Accessed 12 November 2020.

Adegbehin, L. A., Abayomi, I. O. and Nwaigbo, L. B. (1988). Gmelina arborea in Nigeria, Agric. Sc. 3 (2), 981. 1988.

Akpan, U. G., Kovo, A. S., Abdullahi, M. and Ijah, J. J. (2005). The Production of Ethanol from Maize Cobs and Groundnut Shells. AU J.T. 9(2): $106-110$
Becker, C.E. (2013). "The Clinical Pharmacology of Alcohol". Calif. Med., 113 (3)37-45.

Cavalieri, D., McGovern, P.E., Hartl, D.L., Mortimer, R. and Polsinelli, M. (2003). "Evidence for Saccharomyces cerevisiae fermentation in ancient wine". J. of Mol. Evo., 57 (1)26-32.

Chen, Y., Sharma-Shivappa, R.R., Keshwani, D. and Chen C. (2007). Potential of Agricultural Residues and Hay for Bioethanol Production. Appl. Biochem. Biotechnol. 142:276-290. https://doi.org/10.1007/s12010-007-0026-3

Conn, B. and Barry, J. (2001). "Gmelina New South Wales Flora Online". The plant information Network System. 2.0. Sydney, Australia: The Royal Botanic Gardens and Domain Trust. Retrieved 13 March 2013, 5(9): 66.

Durand, A. (2003). "Bioreactor Designs for Solid State Fermentation". Biochem. Engr. J. 13 (2$3): \quad 113-125 . \quad$ doi: $10.1016 /$ s1369$\underline{703 \times(02) 00124-9}$

Fang, Q.H. and Zhong, J.J. (2002). Submerged fermentation of higher fungus Ganoderma lucidium for the production of valuable bioactive metabolites-ganoderic acid and polysaccharide. Biochem. Engr. J., 10 (1)61-65.

Gangadharan, V. (2012). Materials behind the method. The New Indian Express, 6 (4)2.

Kumar, D, Surya, K. and Verma, R. (2020). Bioethanol production from apple pomace using co-cultures with Saccharomyces cerevisiae in solid-state fermentation. JMBFS. 9(4).742-745. doi: $10.15414 /$ jmbfs.2020.

Larinde, S.L and Aiyeloja, A. A. (2014). Production of Specialty Wood Products from Wood Waste of Selected Timber Species Generated in Furniture Workshops. PAT 10 (1): 67-73 ISSN: 0794-5213 www.patnsukjournal.net/currentissue

Lin, Y. and Tanaka, S. (2006). Ethanol fermentation from biomass resources: current $\mathrm{s}$ and prospects. Appl Micro and Biotech, 69 (5)627-642.

Martin, C., Galbe, M., Wahlbum, C.E., HahnHagerdal, B. and Jonson, L.J. (2002). Ethanol 
Production from enzymatic hydrolysis of Sugar bagasse using recombinant xylose-utilizing Saccharomyces cerevisiae. Enzy. and Microb.Tech., 31 (5)274-282.

Michelle, L.M. (2011). Factors affecting ethanol fermentation via simultaneous Saccharification and fermentation. Biotech., 12 (3)1-42.

Okeke, B.C. and Obi, S.K.C. (1994). Saccharification of agro-waste materials by Fungal Cellulases and Hemicelluases. Biores. Tech., 51 (1)23-27.

Orji, J.1, Kelechi, A., Ejikeugwu, C., Nwachi, A. , Moses, I., Eluu, S. and Ugbo, E. (2016). Bioethanol Production from Corncob Hydrolysed by Cellulase of Aspergillus niger Using Zymomonas mobilis and Saccharomyces cerevisiae Isolated from Palm Wine. Inter. J. of Curr. Res. in Biosci. and Plt. Bio. ISSN: 23498080 3(1): www.ijcrbp.com doi: http://dx.doi.org/10.20546/ijcrbp.2016.301.00 4

Palmqvist, E. (2000). Fermentation of lignocellulosic hydrolysates. Biores. Tech., 16 (2) 25-33.

Priyanka, P. Kumar, D. Shankar, U., Yadav, A. and Yadav, K. (2019). Agricultural Waste Management for Bioethanol Production. https://www.researchgate.net/publication/330 322531 DOI: $10.4018 / 978-1-5225-3540-$ 9.ch001

Rodrigues, J., Faix, O. and Pereira, H. (1998). Determination of lignin content of Eucalyptus globulus wood using FTIR spectroscopy. Holzforschung, 52 (1)46-50.

Saini, J.K., Saini, R. and Tewari, L. (2015). Lignocellulosic agriculture wastes as biomass feedstocks for second-generation bioethanol production: concepts and recent developments. Biotech. 5:337-353 DOI 10.1007/s13205-0140246-5

Sainz, M.B. (2011). Commercial cellulosic ethanol: the role of plant-expressed enzymes. Biofuels, 32 (6): 237-264.

Scully, S. and Orlygsson, J. (2014). Recent advances in second generation ethanol production by thermophilic bacteria. Energies, 8(1), 1-30. https://doi.org/10.3390/en8010001
Shu, S., Zhang, N., Nguyen, N., Grogs, S. and Blackwell, M. (2007). Lab manual for yeast study. Mycology lab Louisiana State University, 11 (4): 34-42.

Subramaniyam, R. and Vimala, R. (2012) Solid State and Submerged Fermentation for the Production of Bioactive Substances: A Comparative Study. Inter. J. of Sci. and Nat. 3(3): 480-486.

Talebnia, F., Karakashev, D. and Angelidaki, I. (2010). Production of bioethanol from wheat straw: an overview of pretreatment, hydrolysis and fermentation. Biores. Tech., 101 (13): 4744-4753.

Tortora, A., Gerard, J., Funke, O., Berdell, R., Case, F. and Christine, L. (2010). Microbiology: An Introduction (10 ed.). San Francisco, CA 94111, USA: Pearson Benjamin Cummings. Volume 5 (6): P.135. ISBN 978-0-321-58202-7.

Williams, M.B. and Reese, D. (2005). Colometric determination of ethyl alcohol. Anal. Chem., 22 (3)1556-1559.

Yanase, H., Nozaki, K. and Okamoto, K. (2005). Ethanol production from cellulosic materials by genetically engineered Zymomonas mobilis. Biotech. Lett.s, 27 (3)259-263.

Yanowitz, J. and Mc-Cormick, R. (2009). Standard Specification of Fuel Ethanol for Automotive Spark-Ignition Engines. J. of the Air and Waste Mgt. Ass., 59 (4)172-173. 